\title{
EXPERIMENTALISMO E ESTRATÉGIA: O PROJETO ARTE / CIDADE E A SECRETARIA DE ESTADO DA CULTURA DE SÃO PAULO
}

Gabriel Girnos Elias de Souza

Professor do Curso de Design da Universidade Estadual de Maringá UEM

\section{Introdução}

As relações entre a experimentação artística e os espaços e meios institucionais são permeadas por interesses, táticas, rupturas e alianças diversas, que variaram em forma e significado de acordo com o caso e situação histórica.

Entre a crise das instituições culturais após o governo Collor até as privatizações e a preponderância definitiva das "parcerias" público-privado e da renúncia fiscal para o fomento à cultura, a década de noventa mudou a situação institucional e artística do Brasil. Ocorreu então uma transição de uma produção artística predominantemente apoiada em instituições públicas para uma produção mais ampla, mais comercial e mais dependente de interesses da iniciativa privada (embora ainda financiada em grande parte por dinheiro público). É nessa mesma época que, com a ascensão de uma cultura de grandes eventos e exposições espetaculares, ocorre aqui o processo em que parte da elaboração e "autoria" das realizações do meio artístico se deslocou dos artistas para os organizadores e curadores.

Uma das experiências artísticas que servem de exemplo desse momento de transições é o Projeto Arte/Cidade. De autoria e coordenação do filósofo e curador Nelson Brissac Peixoto, o projeto foi a maior iniciativa de intervenções artísticas em espaços urbanos já feita no país, tendo desenvolvido quatro eventos na cidade de São Paulo entre 1994 e 2002: Cidade sem Janelas (1994), A Cidade e seus Fluxos (1994), A Cidade e suas Histórias (1997) e Arte/Cidade Zona Leste (2002). Considerado um dos mais relevantes empreendimentos culturais das últimas décadas, Arte/Cidade foi ele mesmo foi uma empreitada criada em um órgão público, mas que depois passou a ser gerida a por uma associação, o "Grupo de Intervenção Urbana",

1 O desenvolvimento completo do Projeto Arte/Cidade na capital paulista é abordado em minha dissertação de mestrado Percepções e Intervenções na metrópole: a experiência do Projeto 
Esta comunicação enfoca o primeiro momento desse projeto, em 1994: quando, ainda como iniciativa pioneira da Secretaria de Estado da Cultura de São Paulo, Arte/Cidade lança suas duas primeiras edições. Este texto não se concentrará nas exposições e obras, mas sim em peculiaridades do projeto como proposta curadorial, formato cultural e experiência artística em meio a um momento de transformação de políticas culturais.

\section{As exposições}

A primeira exposição de Arte/Cidade ocorreu em março de 1994, com o nome de Cidade sem Janelas, e ocupou a soturna e claustrofóbica edificaçãoruína do antigo Matadouro Municipal (hoje sede da Cinemateca Brasileira) com sons, projeções, imagens, palavras, rochas e buracos no chão. Já a segunda exposição, feita em setembro, chamava-se $A$ Cidade e seus Fluxos, e espalhara-se na movimentação e na abertura grandiosa do Vale do Anhangabaú com holofotes, elevadores, máquinas e estruturas ópticas locadas em pontos do espaço público e em três edifícios antigos previstos para serem reformados e receberem outros usos.

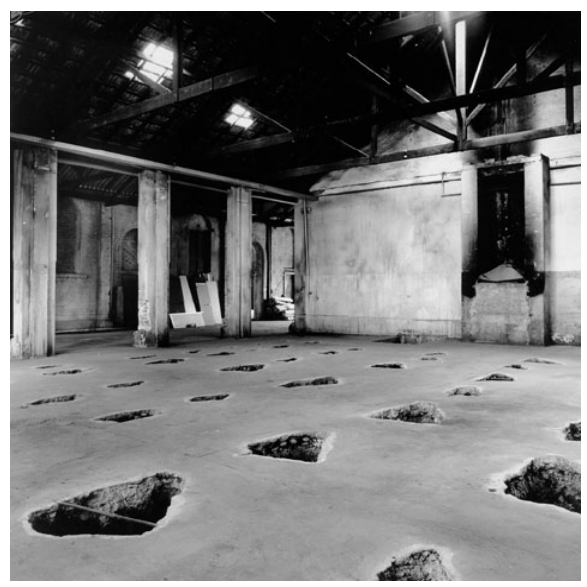

Intervenção de Carmela Gross no Matadouro em Cidade sem Janelas (SESCSP, 1994)

Arte/Cidade em São Paulo: 1994-2002. O presente texto foi construído a partir de excertos do $3^{\circ}$ capítulo desta, "o experimental e o institucional". O projeto Arte/Cidade ainda existe, embora esteja agora dissociado de São Paulo. Para informações a respeito de seu andamento, ver o site www.pucsp.br/artecidade. 


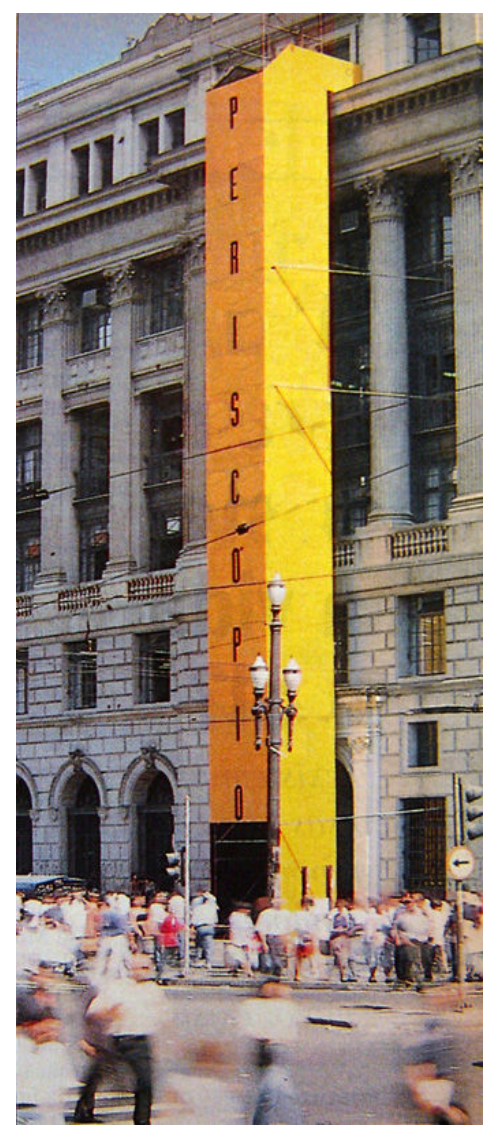

Intervenção de Guto Lacaz no edifício da Eletrobrás (hoje Shopping Light) em A Cidade e seus Fluxos (Revista Veja, 1994)

Os discursos que acompanhavam essas mostras demonstravam um interesse pela cidade que transcendia o da simples locação. O nome dado ao projeto do qual eram parte, por sua vez, era uma sobreposição simples e quase publicitária, que sugeria implicações múltiplas e abrangência ambiciosa: Arte/Cidade.

Intervenções e eventos de arte no espaço urbano não eram exatamente novidades em São Paulo. Mas logo em seu início, o Projeto Arte/Cidade se destacava das iniciativas anteriores e do circuito cultural de então por uma conjunção de fatores, entre eles: 
- pela proposta de um processo coletivo de diálogo entre diferentes linguagens artísticas;

- pela presença de artistas consagrados dessas várias linguagens, como Arthur Omar (vídeo), José Resende e Waltércio Caldas (escultura) e Cássio Vasconcelos (fotografia);

- pela ocupação de lugares degradados e em processo de transição de uso (ainda que já existissem "revitalizações" e transformação de edifícios antigos em centros culturais, esse tipo de abordagem transitória em particular era inédito para uma iniciativa institucional);

- pela proposta de ter obras criadas especificamente para os locais ocupados, partindo justamente de sua condição de transição — ou seja, por ser exemplo das práticas artísticas denominadas de site-specific;

- por possuir uma concentração e um tamanho inéditos para uma iniciativa de arte site-specific no Brasil;

- por receber cobertura excepcionalmente ampla da mídia, e por ter ótima recepção de crítica e de público ${ }^{2}$;

- por ser uma iniciativa não só promovida, mas idealizada e organizada no interior de uma Secretaria de Estado da Cultura - e justamente num momento de crise de instituições culturais públicas, após o governo Collor.

\section{Proposta experimental}

Arte/Cidade começou como um projeto especial da gestão de Ricardo Ohtake na Secretaria de Estado da Cultura de São Paulo (1992-1994). Personagem importante do meio cultural paulistano - é ainda hoje diretor do Instituto Cultural Tomie Ohtake - Ohtake já havia exercido então vários cargos administrativos em instituições culturais públicas ${ }^{3}$. Embora tenha entrado já na metade do mandato de quatro anos ${ }^{4}$, sua gestão teria se caracterizado por projetos e estratégias então pouco comuns à Secretaria -

\footnotetext{
${ }^{2}$ Foram registrados 20 mil visitantes em e 25 mil no segundo2, sem contar os muitos milhares de passantes que teriam visto as obras externas. Números consideráveis para aquele momento.

${ }^{3}$ Relacionados a figuras proeminentes como a artista plástica Tomie Ohtake (mãe) e o arquiteto Ruy Ohtake (irmão), Ricardo Ohtake tornou-se secretário durante o governo estadual de Luis Antônio Fleury Filho (PMDB, 1991-1995). Já havia trabalhado no IDART, no Centro Cultural São Paulo, no Museu da Imagem e do Som (MIS) e na Cinemateca Brasileira, entre outras.

${ }^{4}$ Os dois primeiros anos da gestão da Secretaria estiveram sob cargo de Adilson Monteiro Alves.
} 
entre estas, a formação de um corpo de diferentes assessores, cada um para uma área de produção cultural.

Nesse contexto já bem peculiar, Arte/Cidade se destacava por ser uma proposta que entrelaçava os vários departamentos culturais. E mais ainda, porém, por ser idealizada e organizada por assessores - no caso, Nelson Brissac Peixoto (assessor para audiovisual) e o curador Agnaldo Farias (assessor para artes plásticas) ${ }^{5}$.

O projeto surgiu como uma proposta de exposição "multimidiática" de intervenções artísticas em espaços "esquecidos" da cidade. No princípio, já previa três exposições com temas e contextos urbanos diferentes: $A$ Cidade sem Janelas, que ocuparia um edifício abandonado; $A$ Cidade e seus Fluxos, que se passaria no centro antigo da cidade; e $A$ Cidade e suas Histórias, que teria como cenário e questão as estradas de ferro internas a São Paulo. Segundo Brissac, essa divisão em três blocos não seria uma "trilogia" temática, mas simplesmente o número de exposições que a princípio tinha-se como realizável dentro da gestão Ohtake.

Desde o início, os organizadores ressaltavam Arte/Cidade como iniciativa experimental para uma produção cultural diferenciada. Por um lado, era uma alternativa ao circuito de espaços artísticos convencionais dos museus e galerias, buscando uma fruição diferenciada para as obras de arte em espaços que não fossem "tranquilizadores”(FARIAS, 1994); por outro, era uma alternativa ao isolamento das áreas artísticas, que imperava tanto nas práticas dos artistas quanto no "modo tradicional, compartimentalizado, de incentivo público da produção cultural" (PEIXOTO, 2002, p.12).

O amparo da Secretaria sob a gestão de Ricardo Ohtake teria permitido ao projeto um "acento experimental" (FARIAS, 1994), mas também um considerável senso de oportunidade: em vários aspectos, tratava-se de um projeto extremamente atual.

Arte/Cidade estava afinado com elementos do ambiente intelectual "pós-moderno" de então, como: a crítica às totalizações e pontos de vista hierarquizados; a necessidade de diálogo pluralista entre diferentes perspectivas; a problematização da percepção e da experiência na metrópole contemporânea; a redescoberta estética da cidade.

${ }^{5}$ Além de Brissac e Farias, os o corpo de assessores de Ohtake incluía Guilherme Almeida Prado (cinema), Marta Góes (teatro), Rodolfo Stroeter (música) e Clarisse Abujamra (dança). 
Em um nível mais específico, Arte/Cidade também aparecia em um momento em que diferentes projetos, discursos e iniciativas afirmavam a urgência de se reinvestir e reconsiderar os espaços centrais degradados das cidades (a Associação Viva o Centro em São Paulo é um exemplo). É preciso lembrar que os anos noventa no Brasil foram marcados por projetos de "revitalização" de centros urbanos, e também que nestes a cultura adquiriu papel central como forma de atrair públicos e investimentos. Embora Arte/Cidade não fosse um caso de recuperação patrimonial e marketing urbano, não se pode dissociar a recepção excepcional que obteve do clima geral de "atenção" que pairava sobre os centros urbanos - e que certamente não era desconhecido por seus organizadores.

Existia sim no projeto a idéia de criar um novo uso cultural para espaços degradados à espera de reforma. Mas deve-se ressaltar que, naquele momento, a proposta dava primazia à produção artística. Em outras palavras, não era exatamente um caso de uso da "arte" como ferramenta de valorização da "cidade" (como foi comum na década de noventa e ainda é hoje), mas principalmente um caso de usar a "cidade" como instrumento de valorização da "arte".

A "cidade", no caso, representaria a "realidade" fora dos museus e galerias tradicionais. Nesses primeiros Arte/Cidade, ela serviria como:

- material para uma enriquecer a produção artística;

- um ambiente para ocasionar uma fruição artística nova para o público;

- um "pano de fundo" para catalisar o processo de discussão interdisciplinar, o qual seria talvez a principal proposta do projeto em seu começo.

\section{Arte e instituição}

Do ponto de vista das relações entre instituição e arte, um dos aspectos mais significativos da idéia inicial de Arte/Cidade seria exigir dos artistas participantes um tipo de posicionamento e prática muito diferente daquele ao qual estavam habituados.

A idéia do projeto não era apenas juntar muitas linguagens diferentes, mas construir uma exposição a partir da discussão coletiva entre estas. Mais que disso: ela incluiria diálogo entre diferentes funções do meio artístico. Assim, cada as duas exposições de 1994 foram resultado de um processo de meses de reuniões entre artistas, curadores e críticos de arte, 
nas quais seriam discutidos não apenas as propostas de obra, mas os próprios princípios conceituais do projeto.

Em Arte/Cidade, então, os artistas tiveram de revelar e discutir seus projetos, debater os conceitos da exposição e por vezes tiveram que negociar por si mesmos as condições de realização de seu trabalho diretamente com os agentes da "cidade" real — empresas, instituições e etc.

Em entrevista, artistas como Carmela Gross, Guto Lacaz e Rubens Mano enfatizaram a novidade e riqueza do processo de discussão coletiva proposto, ainda que com seus contratempos e conflitos (SOUZA, 2006, pp.127-128). O escultor Carlos Fajardo, por sua vez, ressaltou em sua entrevista aquilo que considerara uma desorientação existente no processo. Para ele, era como se a discussão coletiva estivesse preenchendo um buraco, realizando uma elaboração que seria trabalho dos curadores; ou seja, haveria um deslocamento dos artistas para realizarem um trabalho que na verdade não seria seu (SOUZA, 2006, p.128).

A perspectiva de Fajardo, tributária de uma divisão talvez mais "tradicional" das funções de curador e artista, traz uma pergunta: o que significaria, na verdade, uma mudança nas práticas de artistas quando não parte destes, mas é proposta por curadores e por instituições?

Mesmo fazendo críticas a aspectos institucionais e deslocando-se destes, Arte/Cidade trabalhava com uma estrutura de prestação de serviços, com comissionamento de artistas e grupos de produção técnica. E é preciso levar em conta que, em última instância, a própria proposta de participação de artistas pode eventualmente servir como instrumento de legitimação de objetivos curadoriais e, em seqüência, de estratégias institucionais.

Do ponto de vista artístico, a "ida à cidade" sugerida pelo projeto Arte/Cidade retomava características e idéias remanescentes do impulso crítico, anti-institucional e anti-objetual das chamadas "neovanguardas" e dos trabalhos site-specific dos anos sessenta e setenta. No limite, a proposta poderia até trazer à mente até a experiência de impressionistas do século XIX em saírem de seus ateliês e pintarem em ambientes urbanos, à luz natural $^{6}$.

${ }^{6}$ A curadoria, coerentemente, evitou de sua parte dar ares excessivos de novidade e vanguardismo ao projeto: “[...] penso que o que nós - coordenadores, artistas e críticos - fizemos aqui, foi simplesmente repropor sem nenhum traço de nostalgia, a consideração desse binômio sem ser de forma anacrônica, avaliando e tirando partido de algumas das experiências anteriormente realizadas." (FARIAS, 1994) 
Mas havia agora a diferença incontornável e decisiva de que se tratava de uma iniciativa institucional a juntar os artistas para a "ida à cidade", e não de uma exploração que partisse deles próprios. E apesar da influência das "neovanguardas" e de possuir uma dimensão crítica ao "cubo branco" museológico, Arte/Cidade era, essencialmente, uma "crítica construtiva", uma ampliação do escopo institucional. Tratava-se, enfim, de uma novidade no ramo das exposições.

A fala dos curadores (FARIAS in SECSP, 1994) se dedicava em particular à idéia de uma nova fruição, a recepção de uma arte que não era objeto ou ambientação autônoma, mas um lugar, uma experiência intransferível. A questão orientadora de Arte/Cidade seria então menos de obras individuais do que do impacto do evento expositivo total e seu background. Assim, a dimensão mais experimental do evento, os muitos improvisos e ações inovadoras envolvidas em sua realização, foram empreitadas feitas a partir de uma perspectiva institucional e organizativa, e não "dos artistas".

Arte/Cidade representaria no Brasil aquilo que a pesquisadora Mion Kwon (2000) chamou de institucionalização das práticas de sitte-specificity. O contextualismo "site-specific" fora originalmente uma prática crítica a um sistema cultural "rígido" e centrado em objetos; agora, ele seria algo estrategicamente interessante para um sistema cultural "flexível" e centrado em eventos.

\section{Estratégia e Atualização cultural}

Da parte da Secretaria de Estado, as possibilidades e objetivos concernentes a Arte/Cidade certamente ultrapassavam a realização artística momentânea. Ainda que só dois Arte/Cidade tenham sido feitos até o final da gestão Ohtake em 1994, a idéia original de se realizar três exposições tão ambiciosas em um único ano é um forte indicador de uma aposta efetiva no futuro daquela prática cultural ${ }^{7}$.

Em sua repercussão, o projeto poderia semear possibilidades de novos formatos e espaços culturais. Esta dimensão mais estratégica da

\footnotetext{
7 O desejo de realizar todo o projeto na gestão Ohtake também seria compreensível em vista da "volatilidade" institucional brasileira. Afinal, no Brasil é sempre difícil contar com continuidade de políticas públicas na mudança de gestões.
} 
proposta estaria exemplificada no seguinte trecho do texto de Ricardo Ohtake para o catálogo da primeira exposição:

Arte/Cidade inscreve-se numa nova visão de cultura, voltada para o incremento dos circuitos de difusão e trocas que vitalizem as diferentes áreas artísticas e espaços culturais. Criar uma dinâmica cultural que proporcione formas mais ricas de espectação e engendre uma demanda mais intensa de novas produções. Com este projeto inauguramos uma nova perspectiva nas atividades culturais: uma série de eventos [...] que atualizem a produção contemporânea. (Ohtake, in SECSP, 1994) ${ }^{8}$

A princípio, é dever de um órgão cultural público fomentar novas realizações e formas de produção. Chama atenção, contudo, o tom enfaticamente empreendedor do Secretário de Estado. Esse tom seria bemvindo diante do imobilismo em geral reinante; mas também é uma característica que se torna mais interessante ao se considerar o momento em que vinha. Tratava-se de uma situação em que se já se instaurava a retórica de "eficiência administrativa", com a emergência de novas instituições e formas de gerência fundadas em lógicas de mercado, que se valiam dos meios de comunicação e de técnicas de marketing e os para ampliar o público e transformar a arte em grande atração (BUENO, 1999, pp. 274-275). Arte/Cidade, afinal, surgira em meio a uma aguda crise institucional; poderia ser que novos "grandes eventos" ousados fossem vistos por aquela gestão como uma estratégia de mudança das políticas culturais?

Nesse sentido, falar em atualização da produção contemporânea, como o fez Ohtake, é algo retoricamente forte; num país eternamente assombrado pelo espectro do atraso, atualizar é sempre um recurso eficiente para a legitimação de empreendimentos (com freqüência empregado pelas instâncias governamentais, em diferentes épocas).

De fato, a idéia de modernização teria desempenhado um papel discreto e indispensável para o sucesso de Arte/Cidade. Já foi comentado aqui que o projeto estava em dia com discussões intelectuais sobre arte e cidade; mas é necessário ressaltar que tanto o uso artístico intermitente de espaços urbanos quanto a organização de grandes eventos eram estratégias em voga no circuito mundial das artes. Desde o final da década de oitenta, existiam projetos contínuos de grandes exposições de arte na cidade, como algumas edições da Documenta de Kassel, o Skulptur Projekte em Münster e o InSite em San Diego e Tijuana.

\footnotetext{
${ }^{8}$ Esse catálogo foi publicado após o grande sucesso de Cidade sem Janelas.
} 
Assim, Arte/Cidade possuiria um aspecto de atualização cultural em relação ao exterior, algo com especial apelo em um país "atrasado" - ainda mais sob a sombra dos processos e dos discursos da "globalização" que então se impunham tenazmente. O projeto seria o precursor nacional de um tipo de empreendimento expositivo relativamente consagrado: a produção de obras site-specific intermitentes para espaços urbanos, organizada e tematizada por curadores, na qual os artistas são convidados a se inserir com seu approach pessoal. Nesse sentido, a prática site-specific iria adquirir por aqui conotações que não seriam nem de "transgressão" e nem apenas de uma "opção", mas também de modernização.

É preciso frisar, contudo, que Arte/Cidade não foi mera cópia de estratégias internacionalmente consagradas. O projeto possuiu parâmetros, discussões e métodos muito próprios. Cidade sem Janelas e $A$ Cidade e seus Fluxos tampouco seriam "megaeventos" seguros como foi, por exemplo, a grande exposição de Rodin na Pinacoteca, em 1995. Sua concretização foi na verdade delicada e incerta. Não haveria patrocinadores, táticas ou mesmo locais bem determinados a priori para o projeto. Embora feitos sob a égide da Secretaria de Estado da Cultura, suas exposições de dependeram desde o início do apoio e patrocínio de outras instâncias públicas e privadas (como a ENSIC S.A., a Cinemídia e a Eletrobrás), de maneira que êxito de cada etapa de Arte/Cidade era praticamente uma condição da existência da etapa seguinte.

O primeiro momento de Arte/Cidade, portanto, formou uma ocasião experimental do ponto de vista de sua organização e da administração pública, mas também "estratégico" do ponto de vista de sua promoção midiática e de suas expectativas de mudança cultural. Como transformação interna a um órgão público, essa ocasião não teve continuidade - foi talvez a última realização tão "alternativa" da Secretaria de Estado naquela década. Como formato de evento cultural, entretanto, o sucesso de suas edições posteriores indica que o projeto foi mais bem sucedido.

\section{Bibliografia}

BUENO, Maria Lúcia. Artes plásticas no século XX: modernidade e globalização. Campinas: Editora da Unicamp, 1999.

FARIAS, Agnaldo A. C. Arte/Cidade. In SECSP. Cidade sem Janelas. São Paulo: Marca D’água, 1994. KWON, Miwon. One place after another: site-specific art and locational identity. Cambridge: The MIT Press, 2002. 
PEIXOTO, Nelson Brissac. Intervenções Urbanas: Arte/Cidade. São Paulo: Editora SENAC São Paulo, 2002.

SECSP (Secretaria de Estado da Cultura de São Paulo). Cidade sem Janelas. São Paulo: Marca D’água, 1994.

SECSP. A Cidade e seus Fluxos. São Paulo: Marca D’água, 1994-2.

SILVA, Fernando de Barros e. "Brissac faz mapeamento da metrópole". Folha de São Paulo, São Paulo, 25/11/1995.

SOUZA, Gabriel G. E. de. Percepcões e Intervenções na Metrópole: a experiência do Projeto Arte/Cidade em São Paulo (1994-2002). Dissertação de Mestrado. São Carlos: EESC-USP, 2006. 